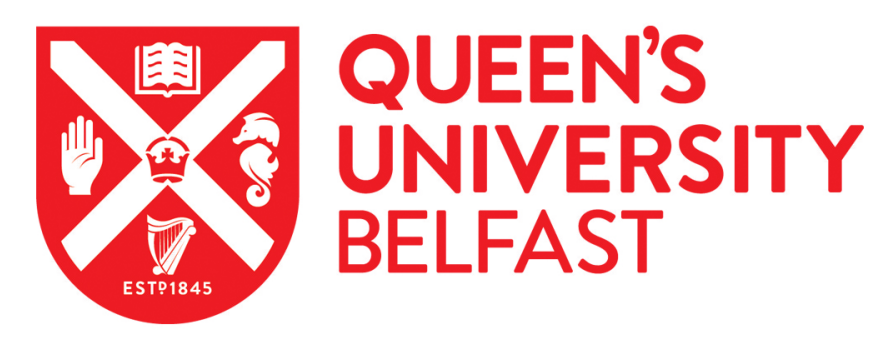

\title{
The effect of high altitude commercial air travel on oxygen saturation
}

Humphreys, S., Deyermond, R., Bali, I., Stevenson, M., \& Fee, H. (2005). The effect of high altitude commercial air travel on oxygen saturation. Anaesthesia, 60, 458-460.

Published in:

Anaesthesia

Queen's University Belfast - Research Portal:

Link to publication record in Queen's University Belfast Research Portal

\section{General rights}

Copyright for the publications made accessible via the Queen's University Belfast Research Portal is retained by the author(s) and / or other copyright owners and it is a condition of accessing these publications that users recognise and abide by the legal requirements associated with these rights.

Take down policy

The Research Portal is Queen's institutional repository that provides access to Queen's research output. Every effort has been made to ensure that content in the Research Portal does not infringe any person's rights, or applicable UK laws. If you discover content in the Research Portal that you believe breaches copyright or violates any law, please contact openaccess@qub.ac.uk. 


\title{
The effect of high altitude commercial air travel on oxygen saturation
}

\author{
S. Humphreys, ${ }^{1}$ R. Deyermond, ${ }^{2}$ I. Bali, ${ }^{3}$ M. Stevenson ${ }^{4}$ and J. P. H. Fee ${ }^{5}$ \\ 1 Anaesthetic Specialist Registrar, Department of Anaesthetics, The Royal Group of Hospitals, Belfast, N. Ireland, \\ BT12 6BA \\ 2 Consultant Anaesthetist, Department of Anaesthetics, Ulster Hospital, Upper Newtownards Road, Dundonald, Belfast, \\ N. Ireland, BT16 1RH \\ 3 Consultant Anaesthetist, Department of Anaesthetics, Antrim Area Hospital, Bush Road, Antrim, N. Ireland, \\ BT41 2RL \\ 4 Lecturer in Medical Statistics, Department of Epidemiology \& Public Health, Queens University of Belfast, Belfast, \\ N. Ireland, BT9 $7 B L$ \\ 5 Professor of Anaesthetics, Department of Anaesthetics and Intensive Care Medicine, Queens University of Belfast, \\ Belfast, N. Ireland, BT9 $7 B L$
}

\begin{abstract}
Summary
Air travel has increased steadily over the last decade, and its effect on the health of passengers has been the subject of much debate. There is a paucity of evidence on the effects of air travel on oxygen saturation in general populations. The peripheral oxygen saturation and pulse rate of 84 passengers, aged 1-78 years, were measured by pulse oximetry at round level and altitude during air travel. There was a statistically significant reduction in oxygen saturation in all passengers travelling long haul and short haul flights $(\mathrm{p}<0.05)$. The mean [range] (SD) $\mathrm{SpO}_{2}$ for all flights at ground level was 97\% [93-100] (1.33) and at cruising altitude 93\% [85-98] (2.33). Fifty-four per cent of passengers had $\mathrm{SpO}_{2}$ values of $94 \%$ or less at cruising altitude. This is a value which may prompt physicians to administer supplemental oxygen in hospital patients.
\end{abstract}

Correspondence to: Susan Humphreys

E-mail:tsgrice@aol.com

Accepted: 24 December 2004

Air travel has grown steadily over the last decade, with up to 1.5 billion passengers flying in commercial aircraft annually. These aircraft are flying at higher altitudes, up to $39000 \mathrm{ft}$ or above. The in-cabin pressure corresponds to an altitude of 5000-6000 ft, and to a fraction of inspired oxygen of $0.17-0.15$ at ground level. Many flights are also of a longer duration than previously, up to $16 \mathrm{~h}$ non-stop $[1,2]$. The reduction in the fraction of inspired oxygen at altitude leads to a reduction in oxygen saturation $\left(\mathrm{S}_{\mathrm{P}_{2}}\right)$ in both healthy passengers and in those with coexisting medical conditions during actual and simulated aeromedical flights [3-7].

The aim of this study was to determine, in a general population, the degree of hypoxaemia during short haul and long haul air travel.

\section{Methods}

Following Regional Ethics Committee approval, and with written informed consent, we measured the oxygen saturation and pulse rate, by pulse oximetry, of 84 passengers aged 1-78 years flying short and long haul in commercial aircraft. Passengers consisted of anaesthetists and their travelling companions and each passenger acted as their own control. No individual had severe cardiorespiratory problems, and no one required permission from their doctor to fly. We have no record of their smoking status. All flights lasted $1 \mathrm{~h}$ or more. The pulse oximeters used were three models of the commercially available Nellcor ${ }^{\mathrm{TM}}$ Oximeter (Pleasanton, CA). Each acted as its own control and these are reported to be accurate at maximum cabin altitude. Data were obtained from flights with more than 10 different airlines. Percentage oxygen saturation and pulse rate were recorded in all passengers at ground level before departure of the aircraft. On short haul flights these measurements were repeated at maximum altitude (that is, maximum cabin depressurisation) as defined by the cabin crew. On long haul flights the second set of measurements were 
taken $2 \mathrm{~h}$ after maximum altitude had been reached. Other parameters recorded included the age of the passenger and the duration of the flight. No consent was sought from the airlines involved.

\section{Statistical analysis}

Paired and unpaired Student's $t$-tests, and one-way ANOVA were used to compare data, as appropriate, with the aid of the graphpad PRISM computer software package. A p-value of $<0.05$ was deemed to be statistically significant.

\section{Results}

Eighty-four passengers were recruited to the study; 55 passengers took long haul flights (duration greater than $2 \mathrm{~h}$ ) and 29 passengers took short haul flights (duration less than $2 \mathrm{~h}$ ) (Figs 1 and 2).

Maximum altitude ranged from 37000 to $41000 \mathrm{ft}$ above mean sea level with an estimated fraction of inspired oxygen concentration of $0.16-0.15$.

As both long and short haul flights showed similar results, the data have been presented together. There was a significant reduction at cruising altitude of $\mathrm{S}_{\mathrm{p}} \mathrm{O}_{2}$ in all passengers, during all flights, when compared to ground level $(\mathrm{p}=0.001)$ (Fig. 2). The mean [range] (SD) $S_{\mathrm{p}} \mathrm{O}_{2}$ at ground level was 97\% [93-100] (1.33) and at cruising altitude 93\% [85-98] (2.33). There was no significant change in pulse rate, the mean [range] (SD) at ground level being $82 \mathrm{bpm}$ [55-128] (16.7) and at cruising altitude $80 \mathrm{bpm}$ [62-118] (13.1).

Using one-way analysis of variance the actual change in $S_{\mathrm{pO}_{2}}$ as a function of each airline was greater for passengers on some airlines than for those on other airlines. The final value was seen to be a function of the starting value and was significant with respect to age; older people started low and ended low.

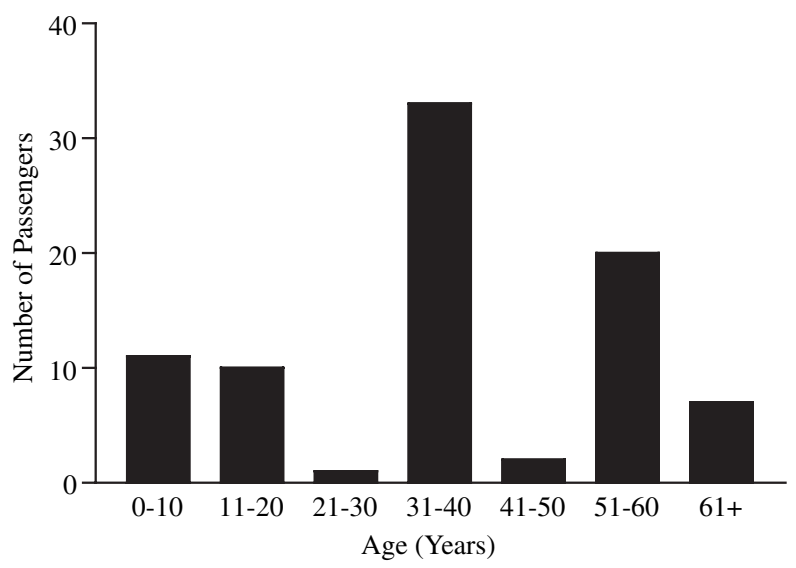

Figure 1 Bar chart illustrating the number of passengers in each age group for all flights $(n=84)$.

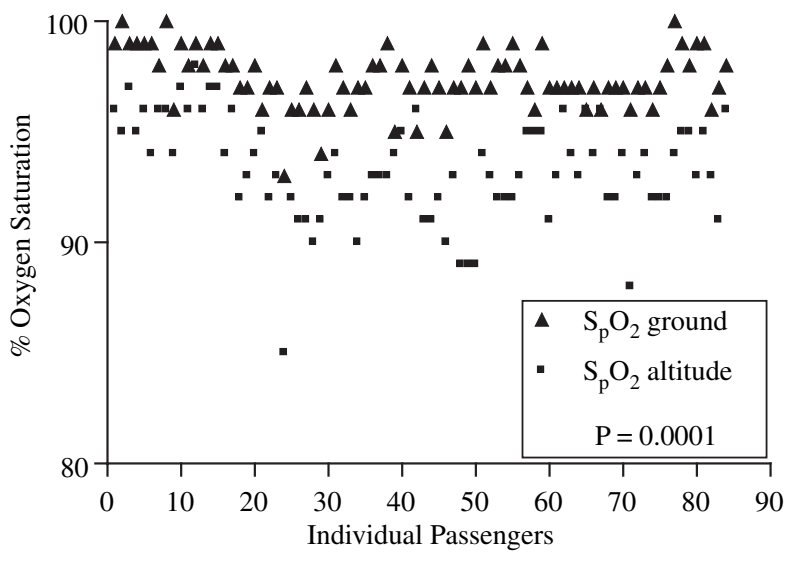

Figure 2 Scattergram illustrating percentage oxygen saturation at altitude and at ground level during all flights $(n=84)$.

\section{Discussion}

The House of Lords and Department of Transport have both acknowledged that more studies need to be carried out with respect to the effects of air travel on health, as there is little information on the physiological effects of flying on passengers currently available [7, 8].

There has been much media and public interest recently in the safety of air travel. This has largely focused on the apparent increase in deep venous thrombosis (DVT) and pulmonary emboli occurring in individuals who have recently flown in commercial aircraft [9]. To date, most of the research surrounding the safety of air travel in respect to deep venous thrombosis has concentrated on the general immobility and dehydration of passengers throughout the flight [10].

Three predisposing factors for DVT are reduced flow, increased coagulability and damaged vessel walls. Limb oedema is believed to be greater in aircraft than for equivalent periods of travel in cars or trains, and to be worse at lower cabin pressures. This may be due to local hypoxia, which causes vasodilation and increased capillary permeability. The ventilation system of aircraft is determined by the required air quality rather than the oxygen supply, for example to dilute human body odour and $\mathrm{CO}_{2}$ to an acceptable level [11]. There is a paucity of data, however, on the quality of this air and on the effect of this quality on the $S_{\mathrm{p}} \mathrm{O}_{2}$ of the individual passengers. Pressurised aircraft do not maintain a sea level pressure during flight for practical reasons. During commercial flights most cabins are pressurised to an equivalent altitude of 5000-8000 ft, which equates to an inspired oxygen fraction of $0.17-0.15$ at sea level [5]. Current US Federal Aviation Regulations specify that pressurised cabins must provide a cabin pressure altitude of not more than $8000 \mathrm{ft}$ $(2440 \mathrm{~m})$ at the maximum operating altitude of the 
airplane (FAA, 1996), in order to maintain the partial pressure of oxygen [12].

Actual cabin altitude pressure measurements by 28 airlines range from sea level to $8,915 \mathrm{ft}(2717 \mathrm{~m})$ with a mean altitude of $6214 \mathrm{ft}(1894 \mathrm{~m})$ and the flying altitude of the planes ranging from $10000 \mathrm{ft}(3053 \mathrm{~m})$ to $60000 \mathrm{ft}(18290 \mathrm{~m})$. The newer aircraft fly higher than older aircraft, with greater altitude exposure to passengers and an increased risk of hypoxia [1]. In our study the maximum altitude of the aircraft was 27 000-37 $000 \mathrm{ft}$, potentially reducing the partial pressure of oxygen, although we did not formally ascertain this value in our study.

Alveolar oxygen tension is known to decrease to $65 \mathrm{mmHg}$ at $8000 \mathrm{ft}$, with a resultant reduction in arterial oxygen tension to $60 \mathrm{mmHg}$ in healthy individuals [1]. Hypoxaemia augments the sympathetic nervous system and has many physiological effects. There is an increase in ventilatory effort in response to hypoxic conditions and the cardiovascular system responds by elevation of the heart rate, with subsequent reduction of stroke volume and an increased risk of angina and dysrhythmias in coronary patients $[2,13]$. Acute hypobaric hypoxia is also known to induce a hypercoagulable state [14]. The cerebral effects are less clearly defined but include reduced night vision and a reduction in cognitive function $[1,2]$.

When considering $\mathrm{S}_{\mathrm{p}} \mathrm{O}_{2}$ and its effects on partial pressure of oxygen, it is essential to understand the unique characteristics of the oxyhaemoglobin dissociation curve. Our study indicates that passengers flying long and short haul have a significant reduction in their $\mathrm{S}_{\mathrm{p}} \mathrm{O}_{2}$. One passenger had an $S_{\mathrm{pO}_{2}}$ of $94 \%$ at ground level and this decreased to $85 \%$ at altitude, Patients with chronic hypoxia may have a greater reduction in $\mathrm{S}_{\mathrm{p}} \mathrm{O}_{2}$ when they reach high altitude than those with healthy lungs. Over one-third of respiratory physicians would prescribe supplementary oxygen for patients with an $\mathrm{S}_{\mathrm{p}} \mathrm{O}_{2}$ of less than 94\% [15]. Over half the passengers studied fell within this category. We analysed the long and short haul data separately but found no significant difference between the two, and so have combined the data. The passengers in our study had $\mathrm{S}_{\mathrm{p}} \mathrm{O}_{2}$ values at cruising altitude (maximum depressurisation) that correspond to a $\mathrm{pO}_{2}$ value on the shoulder of this curve so that a further small reduction in $\mathrm{pO}_{2}(\mathrm{kPa})$ would result in a large fall in $\mathrm{S}_{\mathrm{p}} \mathrm{O}_{2}$. This could have detrimental effects on all body systems.

In conclusion, this preliminary study is the first study to quantify the reduction of percentage oxygen saturation at high altitude during commercial air travel. It demonstrates that there is a reduction in $S_{\mathrm{p}} \mathrm{O}_{2}$ during both long and short haul flights in all age groups. While this study is purely observational in nature, we postulate that this hypoxia (along with other factors such as dehydration, immobility and low humidity) may be a factor in morbidity during and after air travel.

\section{References}

1 Cottrell JJ. Altitude exposures during aircraft flight: flying higher. Chest 1992; 92: 81-4.

2 Peacock AJ. ABC of oxygen: oxygen at high altitude. British Medical Journal 1998; 317: 1063-5.

3 Cottrell JJ, Lebovitz BL, Fennell RG, Kohn GM. In flight arterial saturation: continuous monitoring by pulse oximetry. Aviation Space and Environmental Medicine 1995; 66: 40-4.

4 Bendrick AB, Nicolas DK, Krause BA, Castillo CY. In flight oxygen saturation decrements in aeromedical evacuation patients. Aviation Space and Environmental Medicine 1995; 66: 126-30

5 Cramer D, Ward S. Assessment of oxygen supplementation during air travel. Thorax 1996; 51: 202-3.

6 Vohra KP, Klocke RA. Detection and correction of hypoxaemia associated with air travel. American Review of Respiratory Disease 1993; 148: 1215-9.

7 House of Lords. Science and Technology, Fifth Report, November 2000. London: House of Lords, 2000.

8 Department of Transport, Local Government and the Regions. Health in Aircraft Cabins, Stage 2, December 2001. London: Department of Transport, 2001.

9 Mercer A, Brown JD. Venous thromboembolism associated with air travel: a report of patients. Aviation Space and Environmental Medicine 1998; 69: 154-7.

10 Alexander JK. Coronary problems associated with altitude and air travel. Review. Cardiology Clinics 1995; 13: 271-8.

11 Brundrett G. Comfort and health in commercial aircraft: a literature review. The Journal of the Royal Society for the Promotion of Health: 2001; 121: 29-67.

12 Anonymous. Code of Federal Regulation, Title 14, Part 25 841. Washington DC: US Government Printing Office, 1986.

13 Eklof B, Kistner RL, Masuda EM, Sonntag BV, Wong HP. Venous thromboembolism in association with prolonged air travel. Dermatologic Surgery 1996; 22: 637-41.

14 Bendz B, Rostrup M, Sevre M, Andersen T, Sandset P. Association between acute hypobaric hypoxia and activation of coagulation in human beings. Lancet 2000; 356: 9242.

15 Coker RK, Partridge MR. Assessing the risk of hypoxia in flight: the need for more rational guidelines. European Respiratory Journal 2000; 15: 128-30. 